\title{
Rocky Road or Clear Sailing? Recent Graduates' Recollections and Reflections of the Doctoral Journey
}

\author{
Jonathan G. Bayley \\ University of Windsor \\ Jason Brent Ellis \\ Ashland University \\ Carla Reis Abreu-Ellis \\ Ashland University \\ E. Kathleen O'Reilly \\ First Nations University of Canada
}

\begin{abstract}
While a large group of students enroll in graduate studies in Canada every year, more than half do not reach degree completion (Elgar, 2003; Baird, 1990). This article highlights recent graduates' experiences of their doctoral studies, including the dissertation process. A questionnaire was applied to 15 institutions of higher education, representing all regions of Canada. A total of 53 questionnaires were returned and analyzed. Findings indicated that doctoral students found several challenges to program completion including funding, interactions with faculty, and the writing of the dissertation. Participants also noted that the Canadian Academy provided them with quality experiences, if not at times, rocky ones. An overview is provided of structures and processes that supported and hindered students' doctoral studies as outlined by Gardner's (2009) conceptual framework of doctoral student identity development.
\end{abstract}

Keywords: higher education; doctoral programs; identity; development

Jonathan G. Bayley, Ph.D. is an Associate Professor in the Faculty of Education at the University of Windsor, where he has served as Associate Dean of Graduate Studies, Research, and Continuing Education and Director of the School of Music. Email: jbayley@uwindsor.ca

Jason Brent Ellis, Ph.D., is an Associate Professor of Educational Technologies in the Department of Curriculum and Instruction in Ashland University's Dwight Schar College of Education. Email: jbellis@ashland.edu

Carla Reis Abreu-Ellis, Ph.D., is an Associate Professor in the Department of Inclusive Services and Exceptional Learners in Ashland University’s Dwight Schar College of Education. Email: cellis1@ashland.edu

E. Kathleen O'Reilly, Ph.D., is an Associate Professor of Indigenous Education at the First Nations University of Canada. Email: esegal@fnuniv.ca

Brock Education, Volume 21, No. 2, Spring 2012, pp. 88-102 


\section{Perspective and Rationale}

In any given year, "more than 100,000 students enroll in masters and doctoral programs at over 40 universities across Canada" (Elgar, 2003, p. 1). Approximately 50\% of these students will not graduate (Baird, 1990). While this may well be "one of academia's well-kept secrets" (Golde, 2000, p. 199), the phenomenon is not a new one. Rates of non-completion have remained consistent over the past 40 years (Lovitts, 1996); however, the growing demand for Ph.D. (Doctor of Philosophy) graduates in both the academic and private sectors of the labor force has caused concern with regard to the program completion rate of students.

The purpose of this article was to highlight recent graduates' first-hand experiences of their doctoral studies, including the writing and completing of their dissertations. Based on the anecdotal responses of participants, an analysis of the factors that supported doctoral students' endeavors, as well as the factors that hindered their progression toward completion were categorized based on Gardner's (2009) conceptual framework, A Model of Doctoral Student Development: Identity Development. Thus, Gardner's framework was utilized to observe whether Canadian doctoral students had similar experiences as their American counterparts, as well as, to identify possible discrepancies in Gardner's model of identity development of doctoral students.

\section{Review of the Literature}

A review of the literature revealed that there have been increased efforts over the past few years to dissect the doctoral experience (Lyons \& Doueck, 2010; Rudestam, 2001); however, much of the research has focused on particular aspects of the doctoral journey (Belcher \& Hirvele, 2005; Johnson \& Conyers, 2001). While some research articles have dealt with individual recollections, (Cole, 1994), the majority of the literature (Bair \& Haworth, 1999; Brause, 2000; Magner, 1999; Mauch \& Birch, 1998; Young, 2001) focused on student retention (Green, 1997) and/or the writing of the dissertation (Baird, 1997; Liechty, Liao, \& Schull, 2009), with specific emphases on the mechanics of writing and guidelines for successful completion.

Astin (1987) proposed that students who become involved during college years have a greater chance of being retained and to complete their college degree. According to Astin (1987) "students learn by becoming involved" (p. 133). Student involvement theories focus on interaction with peers and faculty in both academic and non-academic settings. Research results show that positive student involvement contributes to the development of college students (Astin, 1993; Pascarella \& Terenzini, 2005). Even though most of the research on college student development has focused on undergraduate students, as opposed to graduate students, the model still applies as many doctoral programs have moved to a cohort system to facilitate peer interaction and put in place formal and informal social activities to enhance faculty/student interactions (Gardner, 2009). Gardner (2009) noted that "faculty and student interactions. . . is therefore greatly beneficial not only to students' sense of belonging in the department but also to their future socialization and success" (p. 58). The most important theme in the research literature related to the current study was the socialization of doctoral students, particularly the idea of challenges and supports as being necessary conditions for student development (Gardner, 2009), leading to the successful completion of their studies.

Doctoral students characteristics are typically a diverse group which include "women, students of color, older students, students with children and part-time students" and these "differences play a part in the students' overall satisfaction and integration into their programs" 
(Gardner, 2008, p. 130). Sweitzer (2009) found that doctoral programs fail to acknowledge the diverse needs of doctoral students and to recognize that due to their diverse characteristics they hold other responsibilities beyond their academic pursuits. Further, West, Gokalp, Peñha, Fischer, and Gupton (2011) found that doctoral students face challenges during their program of study that may include lack of time management skills and the inability to develop a positive relationship with their advisors. Students require a support system that helps them work through challenges to complete their degrees successfully (Gardner, 2009).

Advising is an important factor that may influence student retention and graduation at the doctoral level. Barnes and Austin (2009) found that "effective advising is complex rather than formulaic" (p. 311). They noted, "it involves attention both to the research development of students as well as to their overall development of professionals. Additionally . . . exemplary advising includes both intellectual diminution and an affective dimension focused on caring, support and friendliness" (p. 311). To conclude, it is of utmost importance to consider the research findings in the area of college student development and to create programs that provide doctoral students with support systems to assist them through doctoral work. Programs must also challenge their students in order to enhance their professional and personal growth as suggested by Gardner's (2009) model of challenge and support.

\section{Theoretical Framework}

Based on qualitative studies performed with 177 doctoral students in the United States of America, Gardner (2009) proposed a conceptual framework for doctoral student identity development, which is grounded in the idea of growth through challenges and the provision of support. She proposed three phases of the doctoral journey of development; the entry, integration, and candidacy phases. Challenges include such items as admission to the program (entry), coursework and qualifying examinations (integration), and dissertation and the transition to the new professional role as scholar (candidacy). What permeates in Gardner's (2009) discussion of support is the emphasis on how program and institutional scaffolds may be used as supports to face challenges on the rocky road toward program completion. Gardner (2009) observed "new doctoral students have several sources of support, including the fellow students they will meet during orientation, the faculty with whom they will connect and have in their initial courses, and the staff who provide support and direction" (p. 10) at the entry level. She further noted that by the nature of most doctoral programs, students must form deeper relationships with both peers and faculty at the integration level and that there lies a danger in the fact that during the candidacy phase, "support students have had in the past, whether through close peer relationships in coursework or daily interaction with faculty, may disappear, intensifying these challenges" (p. 10). There is a sense of isolation to the end game; a loosening of scholarly social ties that enable the person to complete the final work of the dissertation and pursue his or her own path.

\section{Method}

This research study aimed to capture what Lincoln and Guba (1985) refer to as "an inside perspective (subjective)" (p. 27) of doctoral graduates' experiences; thus, providing the participants with the opportunity to reflect upon, and document their personal experiences. This research employed a questionnaire comprised primarily of open-ended questions that generated 
anecdotal responses, rather than restricting participants to only categorical response items. More specifically, the questionnaire included nine demographic questions, four categorical questions (gender, degree completed, financial support, and whether they considered exiting the program), and 21 open-ended questions that aimed to provide a snapshot of the participants' experiences before, during, and after program completion.

Potential participants had either received doctoral degrees from a Canadian Faculty of Education, and/or were currently employed in a Canadian Faculty of Education and who had completed their doctoral work within the last five years. In order to contact potential participants a letter was written to Deans of Education at Canadian universities, requesting that they act as gatekeepers for disseminating the questionnaire.

A content analysis, a process of qualitative analysis, was performed on the open-ended responses to identify common themes. Patton (1990) defined content analysis as "the process of identifying, coding, and categorizing the primary patterns in the data" (p. 381). In this manner, a textual analysis was performed on the responses by employing an "interpretive means of analyzing data" (Schwandt, 2001, p. 34). The emergent themes are discussed in the context of Gardner's (2009) conceptual framework of doctoral student identity development.

\section{Results}

A total of fifty-three completed questionnaires were received from 15 universities, representing all regions of Canada. Thirty-five participants were women, 16 were men, and two did not identify their gender. The range of participants' time-to-completion for their doctoral programs was eight years (2-10 years), averaging 4.8 years, with the majority completing their degrees within three to five years. The doctoral degrees earned by the participants in the study included 49 Doctorates of Philosophy (Ph.D.) and four Doctorates of Education (Ed.D.).

Gardner's (2009) model of doctoral student identity development is divided into three phases; entry, integration, and candidacy. The model encompasses programmatic and developmental experiences, thus speaking to both personal and professional aspects of development. Participants' perceptions of their personal and professional development during their doctoral journeys were analyzed and presented based on Gardner's phases of identity development.

\section{Phase I: Entry}

Phase I of Gardner's (2009) conceptual framework for doctoral student identity development includes "the time leading up to and continuing through the first year of the doctoral program" (p. 41). Further, the first phase includes "admission, orientation, coursework, initial relationships with peers and faculty, changes in how the student thinks and understands knowledge, the transition from undergraduate to graduate school expectations, and the departure of students that results from the lack of support during these challenges" (p. 42). In this sense, the transition itself leads to development in that "transitions are in and of themselves developmental . . . in which individuals begin to understand themselves and the world around them differently in relation to the context and outcome of the transition" (Gardner, 2009, p. 43). Similarly, participants in this study explained the challenges they faced when making the initial transition in choosing where to pursue graduate work. 


\section{Deciding on where to transition: Choosing a graduate school.}

In a number of instances, participants noted that they employed a variety of research strategies, including Internet searches, reference books, career counseling centers, discussions with (former and current) graduate students, and visiting professors and faculty in order to help them select the program and institution of higher education that best served their needs. Some selected a graduate school based on the perceived reputation of a particular institution, program, and/or faculty member. As one participant explained:

I identified a number of schools that seemed to offer the sort of program I was looking for. . . I did this by talking to faculty members I knew in [my] area, and by finding out where various researchers worked. Once, I had a short list of schools, I sent out applications and then visited the schools that appeared interested in my application. (S35, p. 42)

Preferred cities as places to live also played a role in the selection of graduate schools. "I wanted to go to a university with deep historical roots . . roots embedded in tradition. I also wanted to live in [that city] to experience its multicultural ambiance" (S41, p. 43). Another individual stated that "geographic location and potential quality of living. . . . the aesthetic appeal of a city. . . . a chance to live in a city I would not normally have a chance to live in" ( S42, $\mathrm{p}$. 43) were deciding factors.

Many participants, however, chose graduate schools for pragmatic reasons, such as access to funding and/or proximity to where they were already living and working. Several noted that moving away and giving up their current employment would cause undue hardship. Attending university in another city would have been out of the question.

The support of a mentor and/or advisor also figured prominently in many of the responses, as several participants, as Master's level students, had been encouraged to continue with their studies. Other decisions, however, were more spontaneous. In one case, a recruitment notice with "looking for students" and a professor's phone number displayed on a staff-room bulletin board provided sufficient impetus for a participant to investigate further.

Learning balance. Gardner's (2009) conceptual framework suggests "many students talk about the need to find balance among academic responsibilities, work duties, and personal relationships" (p. 48). Although Gardner does not explicitly note that doctoral students struggle with financing their doctoral programs, participants alluded to the need of finding balance and at times the changing role from breadwinner to dependent.

Categorical data resulting from this study showed that financing the doctoral journey was a challenge and often times a juggling act for the participants. Twenty-five percent of the participants received financial support from their spouses or partners. The same number received financial help from their families. More than $40 \%$ of participants used personal savings, investments and Registered Retirement Savings Plans (RRSP) to help finance their degrees. Twenty percent obtained student loans.

Over $60 \%$ of participants received funding in the forms of research assistantships, awards, bursaries, grants and/or scholarships during their tenure as doctoral students. Nearly half of the participants worked full-time during at least part of their doctoral work. Of those participants who indicated that they had worked "part-time," several reported that the 
cumulative effect of their part-time activities often equaled or exceeded full-time employment. Only three individuals indicated that they had received paid sabbatical leave to pursue a terminal degree.

Slightly less than a third of participants indicated that they were unhappy with the level of financial support they had received. As one participant stated "We support life-long learning,' but we don't pay for it" (S18, p. 60). Even those who received significant funding expressed concerns:

The level of funding is appalling. The financial hardship and sacrifice to do this work is extreme. The living conditions are humiliating. You are vulnerable and exploited at every turn. I worked extremely hard and I was prepared to work and make sacrifices to achieve this dream, but I would never advise anyone else to go through what I went through. And I was one of the lucky ones who obtained support. (S34, p. 61)

Participants expressed concern with accessing grant information and available supports, as well as the considerable amount of time (and in some cases, expertise needed) to apply for grants and/or scholarships.

\section{Phase II: Integration}

Within Gardner's (2009) conceptual framework, Phase II is comprised of challenges such as "establishing competency in subject matter through coursework, deepening peer relationships, establishing a relationship with an advisor, preparing for examinations, changing role from student to professional, departing the program as a result of a lack of support" (p. 62). Further, during this phase doctoral students become producers of knowledge rather than consumers, as well as, proving their knowledge of program competencies through qualifying examinations (Gardner, 2009).

Challenges and supports. Participants noted challenges related to accessibility and levels of funding; program rigidity and bureaucracy; excessive red tape; faculty politics, unsatisfactory interactions with faculty, including advisors and committee members; limited course offerings; and ambiguous, unclear, and/or inflexible program expectations. Compounding these external challenges, participants also identified a number of personal concerns that exacerbated their frustration. Individuals spoke about the isolation, time constraints, challenges in finding quality writing time, financial burdens, lack of balance in their lives, difficulty in maintaining motivation, worries relating to post-graduate employment, and, in some cases, long commutes to attend classes and/or perform research.

Gardner's (2009) framework is a dynamic system in which the doctoral student can move forward and regress between phases. As such, several participants acknowledged that they had experienced feelings of self-doubt, and a general lack of confidence seeing themselves as being "good enough" or competent enough to "do" the academic work. Some worried about their research in terms of its potential value to the profession to "make some sort of contribution." Others found that it was difficult to meet their "own expectations" admitting that they were often unduly hard on themselves. Another stated that maintaining a positive attitude, "in the face of repeated disappointments" (S16, p. 71) was a constant challenge, as was working and coping 
with extensive data, and "figuring out how to write the dissertation" (S7, p. 71). Some participants found the comprehensive and/or candidacy exams intimidating and anxiety inducing.

Participants noted that they benefited from the challenges experienced through academic tasks, but also were enabled through peer support. Being immersed in an academic environment and belonging to a "community of learners" were considered an enriching experience. Moreover, opportunities to interact and collaborate with a cohort of international students and like-minded intellectuals, to participate at conferences, and to teach and work at the university level were all cited as especially rewarding. Participants valued many facets of the overall process, such as attending classes, reading widely in their areas of interest, pursuing their own interests, engaging in research, discussing and debating challenging issues, wrestling with new ideas, and working with interesting professors, fellow students, and research participants. Many welcomed the change of pace and the chance to be "immersed in intellectual pursuits" and "selfguided inquiry."

Incongruent with Gardner's (2009) model, in terms of peers being a source of support, was the fact that the competitive nature of graduate school came as a surprise to some participants. As one stated, "I didn't realize it was so competitive. I hated that aspect of graduate school. Students were cut-throat probably because funds were so tight. They were not there to learn, but to succeed and win. That part was terrible" (S34, p. 73). In this sense peers become part of the challenge associated with graduate studies in that they compete for the same limited resources such as funding.

\section{Phase III: Candidacy}

According to Gardner (2009), phase III "is the time during which the doctoral candidate begins to produce original research in the form of the dissertation" (p. 77). In this phase the candidates are faced with the challenge and autonomy of writing the dissertation and often shed their previous social ties with peers and faculty in order to complete the work (Gardner, 2009).

Challenges and supports. Several participants reported that they had problematic experiences with their advisors and/or committee members, particularly in relation to the time it took to receive feedback about their work, and the need to "satisfy all team members who had various backgrounds and points of view" (S6, p. 71). It appeared to some that the "the various processes of the doctoral program were not well understood by most of the faculty personnel" (S7, p. 67). Furthermore, there were concerns that committee members were not well prepared. As one participant stated, "My committee members did not appear to understand the type of research I was doing. Often they did not attend committee meetings or read what I had given them to review. Thus, they could not discuss it knowledgeably" (S45, p. 69). There were several admissions and some acknowledgment that "committee members were overworked [and were] too busy to read and respond to drafts" (S12, p. 67).

Other participants were troubled by what could best be described as "institutional politics" what participants referred to as the "lack of community amongst faculty" and the associated difficulties "negotiating personalities and dynamics among professors and students" (S34, p. 69). The sense of isolation in carrying out the dissertation was also mentioned as one of the more significant barriers to overcome.

Balancing family, work and academic responsibilities were cited as significant challenges to overcome. One participant noted, "Getting up at 4:30 in the morning for several years was the 
only way to keep up" (S13, p. 71). Another stated, "Because I did a lot of teaching, I didn't have the uninterrupted periods of time I needed to think about my data analysis. . . as such, it took a very long time to get this piece of the dissertation completed" (S35, p. 69). The challenge to finish the program in a timely fashion was present in the participants' responses as noted "I think that working part-time whilst holding down a full-time job is always frustrating. Getting the thing finished, in the end, is a burden" (S36, p. 69).

Notable was the stress put on relationships between partners; "My husband always wanted to support me and my work but I think that he considered it to be of little ultimate value and I know that sometimes he despaired of my finishing" (S7, p. 126). Even when both partners were pursuing academic courses, strain was evident: "My spouse and I went through together. Even so, we barely held the marriage together," and "My husband and I began our Ph.D.'s together. We understood each other's stresses and needs, but we often competed with each other when we had common assignments, etc." (S17, p. 127). Two participants in this study noted that they divorced their partner during the course of their doctoral studies.

Time and attention seemed to be the largest factors in the changing relationships. "Through neglect, I lost most of my friends" (S17, p. 127). As one participant aptly noted "my mind was often preoccupied and my time was measured instead of being freely given" (S19, $\mathrm{p}$. 127). Others noted that "There were times I was stressed and unavailable to the important people in my life" (S23, p. 127) or "at times, I became selfish (especially during the writing phase) and forgot about my family (near and extended) relationships" (S43, p. 129), and "I withdrew to get the work done. I had to make a conscious effort to reach out. All of my relationships suffered" (S34, p. 128).

The writing of the dissertation seemed to be the largest observed culprit, which consumed time and attention of participants. In fact, one participant referred to it as a "beast" for such reasons. Another participant offered the following observation in this regard:

For a lot of years I didn't spend much time with my friends, and spent less time with my family than I would have liked. It's hard to agree to do anything social when you know that you have to go home and keep writing the dissertation. Until it's finished, it's very difficult to abandon it. It's a burden that's constantly with you, and it takes a while to disappear even after the dissertation is handed in. (S35, p. 128)

While there was general consensus that the process was often an anxiety inducing challenge, there was acknowledgment that dissertation writing was, at times, both stimulating and invigorating. Several participants spoke about the personal nature and professional development of writing the dissertation. One considered it: "a very personal journey. I learned just as much about myself as I did about my research topic. However, I didn't realize how much until I began to supervise other grad students within months of completing my own doctorate" (S38, p. 138).

Participants found the dissertation process far more demanding and time consuming than what they had originally anticipated. As one participant explained, "It took much longer than planned, but was satisfying in that I remained curious about the topic and committed to its value" (S16, p. 108). There were frustrations expressed concerning timelines, as well as anxiety about the monumental size of the undertaking. "Even though I love writing and all the processes of writing, the writing of my dissertation was painful. It was a huge job. I felt that I was inventing it all [the process] by myself" (S7, p. 104). 
The support and encouragement of advisors, faculty, family, partners/spouses, therapists, and friends were identified as important factors in completing the doctoral journey. An adequate level of funding was also mentioned as a key indicator for successful completion, as was sufficient time to focus on the task at hand - in other words - the luxury of "uninterrupted time to write solidly for three months" (S9, p. 80).

According to participants, the advisor played a prominent role in the doctoral journey. When describing the qualities of a good advisor, participants' responses emphasized both personal and professional characteristics. Professional characteristics included sound knowledge of the field, academic expertise, and current research experience. Participants also stressed the importance of an advisor who would help them procure funding (e.g., teaching assistantships, scholarships and/or grants); assist students with the publishing process; promote and foster academic opportunities (e.g., attending and presenting at conferences); and being thoroughly versed in the mechanics and procedures of the graduate program.

In terms of the more inter-personal characteristics, participants believed that the advisor needed to be, first and foremost, a mentor and genuinely interested in the student's research, interested in the student as a person, engaged in the process, a good listener, supportive, and encouraging. He or she would also have time to meet with the student, as well as provide timely feedback about the student's work. The good advisor would also have a sense of humor and be empathetic, personable, and respectful, as well as provide leadership without being stifling or imposing. Moreover, he or she would be "intellectually vigorous and challenging" (S2, p. 85) and in the words of one participant, know when to "push and when to back off" (S3, p. 85).

Participants identified their personality and will power as personal characteristics that helped them complete their studies as they noted "It was my own determination to complete something I had begun" (S45, p. 83), "my own "striving' nature" (S13, p. 80), "tenacity" (S17, p. 81), and "burning desire to know" (S12, p. 36). They also noted that "having a clear vision about my research and the contribution it would make" (S30, p. 82) and having set goals for the future helped them to get through the dissertation process.

\section{The Contemplation of Program Departure}

Gardner's (2009) conceptual framework notes that students can depart from their doctoral program at any time during the three developmental phases. While all of the participants in this study were successful in completing their doctoral studies, 24 out of 51 participants who responded to this question on the questionnaire acknowledged that at some stage they contemplated not finishing. In aligning the data to Gardner's (2009) model, results from this study indicated that of the 24 students who considered withdrawing from their programs; two of the participants considered exiting their programs sporadically during the three phases; four of the participants considered exiting in phase I (entry); five in phase II (integration); and thirteen participants in phase III (candidacy).

Participants' responses indicated the reasons for considering withdrawal from their programs, included issues related to:

- health (their own or a loved one's)

- feelings of insecurity such as the notion that one was not "good or smart enough,"

- frustration about the length of time and seemingly never-ending process

- loss of a sense of purpose 
- feeling fed up with the process

- loss of ownership of the dissertation

- feelings of isolation and lack of support from the university

- lack of connectedness with faculty

- tensions with advisors and/or committees

- financial hardships

- lack of time to devote to studies because of family and/or work responsibilities.

Participants were most likely to consider departing from their doctoral studies when they felt overwhelmed by the process. For instance, "lengthy, unproductive periods of data analyses" (S35, p. 78), the writing of the dissertation, and the ongoing commitment and length of time required for completion were particularly negative catalysts. "It seemed like I'd be working on the dissertation forever and I couldn't see an end to it" (S35, p. 78). Another participant stated, "the completion point kept moving ahead, eluding my grasp" (S16, p. 76).

Several strategies helped the participants in this study to hang in and finish their programs. Encouragement from advisors and/or committee members; supportive partners, spouses, family members and fellow graduate students; reminding themselves that the degree would lead to improved career opportunities and personal development; and even therapy were identified as significant factors. Fear of failure, pride, the need to stay employed, a realization of the large amounts of money and time already invested in the process were also powerful motivators in deciding to complete the degree.

\section{Implications}

Findings indicated that for doctoral students in the Canadian academy a good academic climate is one that is synonymous with engagement between peers and faculty toward the creation of a community of learners. This notion falls in clear lines with Astin's (1993) discussion on peer groups and student development in that "the student's peer group is the single most potent source of influence on growth and development" (p. 398). Similarly, Astin (1993) observed, "next to peer group, the faculty represents the most significant aspects of the student's undergraduate development" (p. 410). Of course, Astin was discussing the undergraduate years when making these observations, but perhaps the same holds true of graduate studies; or at least graduate students have been conditioned to feel that way during the course of their first four years of higher education. Results of this study noted several participants discussing feelings of isolation. This would denote then that doctoral programs should look at working toward more peer and faculty engagement to quash feelings of isolation by integrating into a community of learners who can support each other through the doctoral journey.

According to the participants in this study, institutions making up the Canadian academy should establish institutional climates where students feel that they have the freedom to pursue their own areas of interest and research. Doctoral students grieve at the loss of ownership of the dissertation and loss of purpose on the rocky road to completion. Perhaps this springs from the dissertation writing process and trying to meet the needs of a diverse committee with perhaps conflicting philosophies. For institutions that consistently observe high levels of attrition of their doctoral students, this may be indicative of problems "in a department, university, or discipline. Those factors that spur attrition in some students may also inflict damage on those who persist" (Golde, 2005, p. 670). Golde (2005) observed that: 
By closely examining the impact of departmental practices and by changing those that do not serve the educational interests of students, departments committed to making improvements would find not only that attrition was reduced but also that the experiences of all students would be enhanced. (p. 696)

The advisor was seen as a catalyst to finishing one's doctoral studies. As Pole and Sprokkereef (1997) observed, doctoral supervisors are often the "principal link between the individual, the department and the institution," (p. 64) and thus:

The supervisor's capacity not only to furnish the student with the required information, but also to provide the route by which the student may become integrated with the institution may be crucial for the progress of the doctorate. (p. 64)

Although guidelines for doctoral supervision exist in several forms, they fail to "cover the range of activities and tasks that supervisors appear to engage in during the course of their involvement with Ph.D. students" (Pole \& Sprokkereef, 1997, p. 49). Participants painted a clear picture of their expectations of what a good advisor should embody, but some noted being constrained by an abusive advisor or those that made decisions without consulting the student. Findings from this research follow the same results of Pole and Sprokkereef (1997) in that doctoral students hold the core expectation that their advisors will be essential in creating a "productive environment in order to progress the research" (p. 64). Most participants acknowledged that while taking on a task of this magnitude was not for the faint of heart, and certainly fraught with its share of academic and even psychological challenges, the process of pursuing doctoral studies was, in the end, a worthwhile and largely satisfying, endeavor.

The model that Gardner has derived from the experience of American doctoral students seems to be highly represented in the experiences of the Canadian doctoral students surveyed in this research. Indeed, Gardner's three phases seem well represented in Canadian students' experiences brought forth here in the form of challenges and supports. The findings of the current study do imply that there may be more to add to the model based on two key issues that have arisen; financing the doctoral degree and its implications on role change and identity formation; and peers not only being seen as supports in the doctoral journey, but also as a challenge in the form of direct competition.

Since all three phases of Gardner's (2009) model include the possibility of program departure it would seem relevant to discuss the financing of the student's programs as a possible attrition factor as either a challenge or form of support. In the current study alone, $25 \%$ of participants noted being supported financially through their programs by a partner or spouse and $25 \%$ by parents or other family members. This may have a profound effect on identity development. Research has been done with young adults, particularly traditional undergraduate students that discuss the converse of this; that is, that individuals see themselves as transitioning to adulthood when they achieve financial independence from their parents and this is a step in identity formation (Settersten, 2006). Also, Arnett (1998) observed that "the criteria most important to young Americans as markers of adulthood are those that represent becoming independent from others (especially from parents)" and principally "accepting responsibilities for one's self, making independent decisions, and financial independence" (p. 296). So the question then arises as to what effect transitioning to financial dependency has on adult identity development? 
Another issue in Gardner's (2009) framework that is somewhat allusive is the question of peers as support or as a challenge. While it is understood from the model that failure to form a supportive peer network can be a factor that lends to program attrition, or as Gardner terms it, "departure," what happens when the peer group actively competes for grades, faculty attention, or resources like assistantships or other means of funding and financial support? Similarly, since family seems to be a primary means of financial support for the doctoral journey, perhaps they also serve as other means of support. Participants talked about family members supporting them by taking on more responsibilities that enabled them to complete the doctoral journey and also discussed family as a means of moral support that urged them to continue when considering withdrawal from their programs. As such, perhaps academic peers are not the only or primary means of support for adult learners. Much like Schlossberg, Waters, and Goodman (1995) have discussed in their transitional model, perhaps a wider definition of support could be useful in Gardner's conceptual framework to include support from intimate relationships, family units, networks of friends (which would include academic peers), and institutions (which would include faculty and advisors). 


\section{References}

Arnett, J. J. (1998). Learning to stand alone: The contemporary American transition to adulthood in culture and historical context. Human Development, 41(5), 295-315.

Astin, A. W. (1987). Achieving educational excellence. San Francisco: Josse-Bass.

Astin, A. W. (1993). What matters in college: Four critical years revisited. San Francisco: JosseBass.

Bair, C. R., \& Haworth, J. G. (1999). Doctoral student attrition and persistence: A metasynthesis of research. Paper presented at the Annual meeting of the Association for the Study of Higher Education, San Antonio, Texas, USA', November 18-21, 1999.

Baird, L. L. (1997). Completing the dissertation: Theory, research, and practice. New Directions for Higher Education, 99, 99-105.

Baird, L. L. (1990). Disciplines and doctorates: The relationships between program characteristics and the duration of doctoral study. Research in Higher Education, 31, 369-385.

Barnes, B. J., \& Austin, A. E. (2009). The role of doctoral advisors: A look at advising from the advisor's perspective. Innovative Higher Education, 33, 297-315. doi: 10.1007/s10755008-9084-X

Belcher, D., \& Hirvela, A. (2005). Writing the qualitative dissertation: What motivates and sustains commitment to a fussy genre? Journal of English for Academic Purposes, 4(3), 187-205).

Brause, R. S. (2000). Writing your doctoral dissertation: Invisible rules for success. London: Falmer Press.

Cole, A. L. (1994). I remember. . Critical incidents in my thesis journey. In A. L. Cole \& D. E. Hunt (Eds.), On behalf of the Thursday Group. The doctoral thesis journey: Reflections from travelers and guides. Toronto, Ontario: OISE Press.

Elgar, F. J. (2003). PhD degree completion in Canadian universities (Final Report). Dalhousie University: Graduate Student Association of Canada.

Gardner, S. K. (2008). Fitting the mold of graduate school: A qualitative study of socialization in doctoral education. Innovative Higher Education, 33, 125-138. doi: 10.107/s10755008-9068-x

Gardner, S. K. (2009). The development of doctoral students: Phases of challenge and support. ASHE Higher Education Report. San Francisco: Jossey-Bass. 
Golde, C. M. (2000). Should I stay or should I go? Student descriptions of the doctoral attrition process. Review of Higher Education, 23, 199-227.

Golde, C. M. (2005). The role of the department and discipline in doctoral student attrition: Lessons from four departments. The Journal of Higher Education, 76(6), 669-700.

Green, K. E. (1997). Psychological factors affecting dissertation completion. New Directions for Higher Education, 99, 57-64.

Johnson, R. W. \& Conyers, L. M. (2001). Surviving the doctoral dissertation: A solution-focused approach. Journal of College Counseling, 4, 77-80.

Liechty, J. M., Liao, M., \& Schull, C. P. (2009). Facilitating dissertation completion and success among doctoral students in social work. Journal of Social Work Education, (45)3, 481497.

Lincoln, Y. S., \& Guba, E. G. (1985). Naturalistic Inquiry. Thousand Oaks: Sage Publications.

Lovitts, B. E. (1996). Who is responsible for graduate student attrition - The individual or the institution? Toward an explanation of the high and persistent rate of attrition. Presented at the Annual Meeting of the American Education Research Association (New York: April 9, 1996).

Lyons, P., \& Doueck, H. J. (2010). The dissertation from beginning to end. New York: Oxford University Press.

Magner, D. K. (1999). Record number of doctorates awarded in 1997. The Chronicle of Higher Education, January 8, A14-15.

Mauch, J. E., \& Birch, J. W. (1998). Guide to the successful thesis and dissertation: A handbook for students and faculty ( $4^{\text {th }}$ ed.). New York, NY: Marcel Dekker.

Pascarella, E. T., \& Terenzini, P. T. (2005). How college affects students: A third decade of research. San Francisco: Josse-Bass.

Patton, M. Q. (1990). Qualitative evaluation and research methods. Thousand Oaks: Sage Publications.

Pole, C. J., \& Sprokkereef, A. (1997). Supervision of doctoral students in the natural sciences: Expectations and experiences. Assessment \& Evaluation in Higher Education, 22(1), 49-64.

Rudestam, K. E., \& Newton, R. R. (2001). Surviving your dissertation: A comprehensive guide to content and process. Thousand Oaks, CA: Sage Publications. 
Schlossberg, N. K., Waters, E. B., \& Goodman, J. (1995). Counseling adults in transition. New York: Springer.

Schwandt, T. A. (2001). Dictionary of qualitative inquiry. Thousand Oaks: Sage Publications.

Settersten, R. A. (2006). Becoming adult: Meanings and markers for young Americans. Network on Transitions to Adulthood Research Network. Retrieved December 15, 2010 from http://www.transad.pop.upenn.edu

Sweitzer, V. B. (2009). Towards a theory of doctoral student professional identity development: A developmental networks approach. Journal of Higher Education, 80(1), 1-33.

West, I. J. Y., Gokalp, G., Peñha, E. V., Fischer, L., \& Gupton, J. (2011). Exploring effective support practices for doctoral students' degree completion. College Student Journal, 45(2), 310-323.

Young, L. J. (2001). Border crossings and other journeys: Re-envisioning the doctoral preparation of education researchers. Educational Researcher, 30(5), 3-5. 